\title{
Assessment of Durability of Recycled Aggregate Concrete Produced by Two-Stage Mixing Approach
}

\author{
Vivian W. Y. Tam ${ }^{1}$ and C. M. Tam ${ }^{2}$
}

\begin{abstract}
As more than $50 \%$ construction and demolition (C\&D) wastes are composed of concrete debris in Hong Kong, recycling this debris into Recycled Aggregate (RA) for production of Recycled Aggregate Concrete (RAC) is an efficient way to alleviate the burden on landfill areas. Since RA is generated from concrete debris which has undergone years of services, the resulting RAC bears the weaknesses of lower density, higher water absorption, and higher porosity that limit them to lower-grade applications. Pinpointing to these weaknesses, Tam et al. [1] developed the Two-Stage Mixing Approach (TSMA) for improving the strength of RAC, leading to the possibility in applying RAC for higher-grade applications. While the improvement in strength by TSMA has been proven in Tam et al.'s work [1], the durability, in terms of deformation (shrinkage and creep) and permeability (water, air and chloride permeability), remains to be verified. In this paper, $0 \%, 20 \%$ and $100 \%$ of RA substitutions have been experimented to compare the durability performance of the Normal Mixing Approach (NMA) and the TSMA. Experiment results highlight that: i) the higher the substitutions of RA, the weaker the performance of RAC; and ii) the deformation and permeability of RAC can be enhanced when adopting TSMA. Therefore, it demonstrates that TSMA can help to improve the durability of RAC, on top of the previously verified strength improvement, and thus opening up wider applications of RAC.
\end{abstract}

Keywords: Deformation, permeability, shrinkage, creep, recycled aggregate concrete.

\footnotetext{
${ }^{1 *}$ Correspondence Author, Lecturer , Griffith School of Engineering, Gold Coast Campus, Griffith University, PMB50 Gold Coast Mail Centre, Qld 9726, Australia. Email: v.tam@griffith.edu.au. Tel: (61) 7-5552-9278; Fax: (61) 7-5552-8065.

${ }^{2}$ Professor, Department of Building and Construction, City University of Hong Kong, Hong Kong.
} 


\section{Introduction}

In recent years, recycling of concrete wastes in producing Recycled Aggregate (RA) has been proven to be commercially viable and technically sound for non-structural applications [2] [3] [4] [5]. Such recycling operations can reduce landfill consumption, while conserving primary resources and reducing transport costs [5] [6]. Some of the examples are shown in Table 1 [7]. $<$ Table $1>$

Although the reuse of demolished concrete waste can benefit the environment, literature reports show that the cement mortar attached to the recycled aggregate particles creates numerical problems that have confined the application of Recycled Aggregate Concrete (RAC) [2] [5] [8] [9] [10] [11] [12] [13] [14] [15] [16] [17] [18] [19] [20] [21] [22] [23] [24] [25] [26] [27] [28] [29] [30] [31] [32]. This residual mortar alters the absorption and density of aggregate, leading to adverse effects on concrete performance.

The worry on the use of RAC is not limited to structural stability, but also their durability in designing concrete structures [24] [33] [34] [35] [36] [37] [38]. Durability plays an important role in the life cycle cost of a structure; for example, in Japan, it is estimated that the maintenance and renovation costs for infrastructure will exceed $70 \%$ of the total public investment in 2010. In the United States, it is estimated that the necessary repairs and improvements to the infrastructure will amount to $\$ 3.3$ trillion over a period of 19 years. Thus, durability has become a matter of social importance.

To improve the quality of RAC, a new mixing method: Two-Stage Mixing Approach (TSMA) has been developed by Tam et al. [1]. The improvement is achieved by forming a layer of cement slurry on the surface of RA to fill up the cracks and voids, leading to an improved 
interfacial zone at the pre-mix stage. The improvement of strength on TSMA has been proven by Tam et al. [1] while the performance on durability remains to be studied. The factors affecting concrete structures’ durability have been reported by many researchers. Most agree that deformation (in the forms of shrinkage and creep) and permeability (in the forms of water, air and chloride permeability) are good and reliable indicators to assess the long-term durability of concrete [24] [33] [34] [35] [36] [37] [38].

This paper aims in: i) exploring the Two-Stage Mixing Approach (TSMA) developed by Tam et al. [1] by highlighting the improvements to RAC; and ii) experimenting the durability performance of RAC in terms of deformation (in the forms of shrinkage and creep) and permeability (in the forms of water, air and chloride permeability) so achieved by TSMA.

\section{Experimental Work}

\section{$2.1 \quad$ Methods and Material}

In investigating the behaviour of RAC, RA was collected from the centralized recycling plant at Tuen Mun Area 38, which has met the specification of the Buildings Department (BD) of the Hong Kong Special Administrative Region (SAR) [39]. In producing RAC, RA is required to be thoroughly wetted before use and follow the designated mix proportions (see Table 2) with a water to cement ratio of 0.45 . The ratio of ordinary Portland cement: fine aggregate: $20 \mathrm{~mm}$ coarse aggregate: $10 \mathrm{~mm}$ coarse aggregate: water is 1: 1.8: 1.8: 0.9: 0.45. As the Hong Kong government recommends a limit of 20\% RA substitution [24] [40] [41], 0\%, $20 \%$, and $100 \%$ of RA substitutions have been experimented using the Two-Stage Mixing Approach (TSMA) in comparison with those made with the Normal Mixing Approach (NMA).

$<$ Table 2> 
For NMA, the mixer is first charged with about one half of coarse aggregate, then with fine aggregate, then with cement and finally with the remaining coarse aggregate; water is then added immediately before the rotation of the drum or starting the pan [42]. In contrast, TSMA divides the mixing process into two parts and proportionally splits the required water into two which are added at different times. Figure 1 illustrates TSMA mixing procedures.

$<$ Figure 1 $>$

From the study of Tam et al. [1], improvements in strength can be achieved up to $21.19 \%$ for TSMA (with 20\% RA replacement after 28-day of curing). During the first stage of mixing, it uses half of the required water for mixing leading to the formation of a thin layer of cement slurry on the surface of RA which will permeate into the porous old cement mortar, filling up the old cracks and voids. At the second stage of mixing, the remaining water is added to complete the concrete mixing process. As a result, improvements in strength have been recorded in the works of Tam et al. [1]. However, the lack of data on durability hinders the large-scale adoption of this economic and environmentally friendly mixing approach. Therefore, the long-term performance still needs to be examined.

A review of the literature unveils that there are limited studies on the durability of RAC. Drying of concrete occurs in a non-homogeneous manner leading to a strong structural effect; self-equilibrated stresses do arise within the material [43]. The intrinsic behaviour of the deformation of concrete can therefore be deduced in a sort of inverse analysis by focusing on the conventional components: drying shrinkage and creep. Furthermore, the permeability in concrete is a material characteristic bearing a significant influence on concrete durability, specifically regarding freeze-thaw resistance, resistance to chemical attack, and alkali- 
aggregate reactions [44]. They are considered the important indicators of concrete quality. Table 3 summarizes the standard methods used in testing the performance of RAC.

$<$ Table 3>

\subsection{Experimental Results}

Although the use of RAC is an effective method in reducing the problems of C\&D waste, the problems associated with the quality of RAC are of grave concern. The most important factor influencing the quality is the high water absorption due to the large amounts of old cement mortar attached to the RA. The use of RAC generally leads to about $10 \%$ reduction in the compressive and tensile strength, up to $35 \%$ reduction in modulus of elasticity, nearly $100 \%$ increase in drying shrinkage and 100\% increase in the permeability [26] [41]. As a result, the durability of RAC is lower than that of normal concrete [45]. The physical and mechanical properties, durability and deformation become worse when increasing the RA replacement ratio.

\subsubsection{Deformation}

Deformation is measured by two tests: shrinkage and creep. A saturated cement paste will not remain dimensionally stable when exposed to ambient humidity that is below saturation. This is mainly because of the loss of physically absorbed water from Calcium Silicate Hydrate [CaO.SiO $\mathrm{CH}_{2} \mathrm{O}$ or $\mathrm{CSH}$ ] [46] [47] [48] [49], resulting in a shrinkage strain. Similarly, when a hydrated cement paste is subjected to a sustained stress, depending on the magnitude and duration of applied stress, CSH will lose a large amount of the physically absorbed water and the paste will show a creep strain.

The time-dependent properties of concrete have been researched since the early decades of 
the last century [50]. Deformation is a complex phenomenon which is influenced by many factors including the constituents, the temperature and relative humidity of the environment, the age when the concrete is subjected to the drying environment and the size of the structure or member [3] [46] [47] [48] [51] [52] [53]. Factors affecting deformation are summarized in Table 4.

$<$ Table 4>

As regards shrinkage of concrete specimens, Table 5 summarizes the average results of the six tests with the change of deformation behaviour shown in Figure 2. Similarly for creep, Table 6 summarizes the average results of the four tests with the change of deformation behaviour shown in Figures 3.

$<$ Table 5>

$<$ Table 6>

$<$ Figure 2>

$<$ Figure 3>

Porosity of aggregate can influence the deformation of concrete samples [49]. Therefore, RA usually leads to higher shrinkage and creep, mainly because the aggregate provides less restraint to the potential deformation of cement paste [3] [5] [54] [55] [56]. Experimentation highlights the increases in shrinkage, creep strain and creep coefficient at $0.131 \%, 0.001517$ and 15.1667 with $100 \%$ RA substitution and $0.121 \%, 0.000563$ and 5.633 with $0 \%$ RA substitution respectively for NMA after 182 days of curing. The creep rate $[F(K)]$ listed in Table 7 shows that a higher substitution of RA will accelerate the creep deformation. For example, 0.00005 strain/day can be recorded on $100 \%$ RA substitution and 0.00002 strain/day can be recorded on 0\% RA substitution for NMA. However, the difference 
between $0 \%$ and $20 \%$ of RA substitutions is not significant.

$<$ Table 7>

Although there is an increase in deformation after the adoption of RA, TSMA helps reduce its impact. From the experimental results, the reduction on creep strain for TSMA is proven; for example, 0.001176 is measured for TSMA and 0.001517 is measured for NMA with $100 \%$ RA substitution after 182 days of curing. Creep coefficients obtained give similar results at 11.7611 for TSMA and 15.1667 for NMA with $100 \%$ RA substitution after 182 days of curing. An improvement of creep rate $[F(K)]$ is recorded with $20 \%$ RA substitution at 0.00002 strain/day for TSMA and 0.00003 strain/day for NMA. However, under the controlled humidity condition, the performance in shrinkage did not provide any significant difference between the traditional process and TSMA with the same RA substitution. Furthermore, the deformation of RAC can be improved after adopting TSMA by up to $68.09 \%$ in shrinkage and $46.42 \%$ in creep (as in the case of $100 \%$ RA substitution after 14 days of curing).

After measuring the deformation behaviour in terms of shrinkage and creep, the performance of concrete in reversibility and irreversibility after rewetting and unloading the samples are investigated [49]. In the case of shrinkage, it can be categorized into reversible shrinkage, which is the part of total shrinkage that is reproducible on wet-dry cycles; and irreversible shrinkage, which is the part of total shrinkage on first drying that, cannot be reproduced on subsequent wet-dry cycles. The reversible shrinkage is probably due to development of chemical bonds within $\mathrm{CSH}$ structure. The irreversible part of shrinkage is associated with the formation of additional physical and chemical bonds in the cement gel when absorbed water has been removed [47]. The case on creep is similar. The developments of shrinkage and creep are illustrated in Figure 4. It can clearly illustrate that the development of the curves of 
shrinkage and creep in the samples are very similar as that in Figure 4.

$<$ Figure 4 $>$

In this research, rewetting and unloading the samples are exercised after 28 days of measurement. The results show that the reversible parts of shrinkage and creep gained from TSMA are better than those from NMA (see Table 8). For example, $28.70 \%$ and $51.11 \%$ can be reversed for TSMA and $24.56 \%$ and $51.02 \%$ can be reversed for NMA on shrinkage and creep respectively with $100 \%$ RA substitution after 182 days of curing. However, the difference between $0 \%$ and $20 \%$ RA substitution is not significant.

$<$ Table 8>

\subsubsection{Permeability}

Penetration into and leaching out of concrete by materials in solution may adversely affect its durability, for instance when Calcium Hydroxide $\left[\mathrm{Ca}(\mathrm{OH})_{2}\right]$ is being leached out or an attack by aggressive liquids takes place. This penetration depends on the permeability of the concrete, which is defined as the property that governs the rate of flow of a fluid into a porous solid [32] [44] [47] [48] [57] [58]. Since permeability determines the relative ease with which concrete can become saturated with water, permeability has an important bearing on the vulnerability of concrete to frost. Furthermore, in the case of reinforced concrete, the ingress of moisture and of air and chloride will result in the corrosion of steel. Since this leads to an increase in the volume of the steel, cracking and spalling of the concrete cover may well follow [49]. In this paper, three types of permeability tests are experimented: water permeability, air permeability and chloride permeability. Tables 9, 10 and 11 summarize the results on water, air and chloride permeability respectively.

$<$ Table 9>

$<$ Table 10> 
In a hydrated cement paste, the size and continuity of the pores at any point during the hydration process would control the coefficient of permeability. The mixing water is indirectly responsible for permeability of the hydrated cement paste because its content determines the total space and subsequently the unfilled space after the water is consumed by either cement hydration reactions or evaporation to the environment [47]. The permeability of concrete is affected by its porosity, and size, distribution and continuity of the pores [49]. The experimentation highlights the reduction on the performance of permeability with higher substitutions of RA (see Tables 9, 10 and 11). For examples, the water, air and chloride permeabilities obtained are $0.001642 \mathrm{~mm}^{2} / \mathrm{s} . \mathrm{BAR}, 4.5470 \mathrm{~s} / \mathrm{ml}$ and 2906.60 amperes.s with 100\% RA substitution compared to $0.001284 \mathrm{~mm}^{2} / \mathrm{s} . \mathrm{BAR}, 9.0082 \mathrm{~s} / \mathrm{ml}$ and 2231.56 ampere.s with 0\% RA substitution for NMA under 182 curing conditions. However, the difference is not significant for RA replacements between $0 \%$ and $20 \%$.

Although the adoption of RA will weaken the performance of RAC [24] [32], TSMA helps alleviate the problem as a reduction in the volume of large capillary voids in the paste matrix would certainly reduce the permeability. Since the porosity of RA is reduced by the provision of the cement gel surrounding RA in the pre-mix stage of TSMA, permeability can be improved (see Tables 9, 10 and 11). For examples, the water, air and chloride permeability obtained are $0.001544 \mathrm{~mm}^{2} / \mathrm{s} . \mathrm{BAR}, 9.7374 \mathrm{~s} / \mathrm{ml}$ and 2906.60 amperes.s for NMA compared with $0.001501 \mathrm{~mm}^{2} / \mathrm{s}$.BAR, $11.2817 \mathrm{~s} / \mathrm{ml}$ and 2578.04 ampere.s for TSMA on 20 percent of RA substitution under 182 curing conditions. Furthermore, the improvement of TSMA can be up to $35.41 \%$ on water permeability (as in the case of $100 \%$ RA substitution after 126 days of curing), $51.81 \%$ on air permeability (as in the case of $20 \%$ RA substitution after 56 days of 
curing) and $29.98 \%$ on chloride permeability (as in the case for 100\% RA substitution after 126 days of curing).

From the above tests, it is obvious that TSMA can help improve the durability, in terms of deformation and permeability, of the RAC. During the first stage of mixing, TSMA uses only half of the water for mixing to form a thin layer of cement slurry on the surface of RA which will permeate into the porous old cement mortar, filling up the old cracks and voids [Figures 5 shows the filled crack after using TSMA, while Figure 6 shows the unfilled crack after using NMA]. At the second stage of mixing, the other half of water is added to complete the concrete mixing process. The experimentation shows that TSMA can enhance the performance of RAC by the development of a stronger interfacial zone in comparison with the traditional process (see Figure 7 for TSMA and Figure 8 for NMA). The quality of ITZ depends on surface characteristics of the aggregate particles, the degree of bleeding, chemical bonding and the specimen preparation technique which, however, are notoriously difficult to measure. Although these effects have been reported by some investigation, the results are difficult to reconcile. Nonetheless, it is generally agreed that as the paste-aggregate bond strength increases, the concrete strength also increases [48]. Figure 9 highlights the fracture mode for TSMA which is not around ITZ, while that for NMA is. It is therefore proved that TSMA can improve the ITZ of RA and thus the strength and durability of RAC. Figure 10 illustrates the concrete matrix scenario for NMA and TSMA schematically.

\footnotetext{
$<$ Figure $5>$

$<$ Figure 6>

$<$ Figure 7>

$<$ Figure 8>

$<$ Figure 9>
} 
$<$ Figure 10>

\section{Conclusion}

The poor quality of RAC resulted from higher water absorption, higher porosity, weaker ITZ between RA and new cement mortar hampers the application of RAC for higher grade applications. Two-Stage Mixing Approach (TSMA) has been proposed by Tam et al. [1] to strength the weak link of RAC, which is located at the Interfacial Transition Zone (ITZ) of the RA. The TSMA allows the cement slurry to gel up the RA, providing a stronger ITZ by filling up the cracks and pores within RA. The improvements of strength after adopting TSMA have been proven by the works of Tam et al. [1]; the durability on deformation and permeability have been explored in this paper. Experimentation highlights that:

(a) The higher the substitutions of RA, the weaker the performance of RAC; and

(b) The deformation and permeability of RAC can be enhanced by adopting TSMA with up to

(i) $\quad 68.09 \%$ on shrinkage (with $100 \%$ RA substitution after 14 days of curing);

(ii) $\quad 46.42 \%$ on creep (with $100 \%$ RA substitution after 14 days of curing);

(iii) $\quad 35.41 \%$ on water permeability (with $100 \%$ RA substitution after 126 days of curing);

(iv) $\quad 51.81 \%$ on air permeability (with 20\% RA substitution after 56 days of curing); and

(v) $\quad 29.98 \%$ on chloride permeability (with $100 \%$ RA substitution after 126 days of curing).

Therefore, this demonstrates that TSMA can provide an effective method for enhancing durability, in addition to the previously verified strength improvement, and thus the approach opens up a wider scope of RAC applications. 


\section{Acknowledgments}

The work described in this paper was fully supported by a grant from the Housing Authority Research Fund of the Hong Kong Special Administrative Region, China (Project Ref. No. 9460004).

\section{References}

[1] W.Y.V. Tam, X.F. Gao, C.M. Tam, Micro-structural analysis of recycled aggregate concrete produced from two-stage mixing approach, Cement and Concrete Research 35(6), (2005), 1195-1203.

[2] S. Coventry, The reclaimed and recycled construction materials handbook (London: Construction Industry Research and Information Association, 1999).

[3] C.F. Hendriks, H.S. Pietersen, Sustainable raw materials: construction and demolition waste (RILEM Publication, Cachan Cedex, France, 2000).

[4] N. Masters, Sustainable use of new and recycled materials in coastal and fluvial construction: a guidance manual, in: (London: Thomas Telford, 2001).

[5] K.K. Sagoe-Crentsil, T. Brown, A.H. Taylor, Performance of concrete made with commercially produced coarse recycled concrete aggregate, Cement and Concrete Research 312001), 707-712.

[6] A.P. Carneiro, J.C. Cassa, I.A. DeBrum, A.M. Vieira, A.D.B. Costa, T.S. Sampaio, E.P.V. Alberte, Construction waste characterization for production of recycled aggregate - Salvador / Brazil, in: Waste materials in construction: WASCON 2000: proceedings of the International Conference on the Science and Engineering of Recycling for Environmental Protection (Harrogate, England, 2000) 825-835. 
[7] H. Kawano, Barriers for sustainable use of concrete materials, Concrete technology for a sustainable development in the 21st century (London: New York: E \& FN Spon, 2000) 288-293.

[8] P.C. Aitcin, A.M. Neville, High performance concrete demystified, Concrete International 15(1), (1993), 21-26.

[9] M.G. Alexander, The effects of ageing on the interfacial zone in concrete, Interfacial transition zone in concrete: state-of-the-art report1996), 150-174.

[10] D.P. Bentz, E.J. Garboczi, Simulation studies of the effects of mineral admixtures on the cement paste-aggregate interfacial zone, ACI Materials Journal SeptemberOctober1991), 518-529.

[11] N. Buch, M.A. Frabizzio, J.E. Hiller, Impact of coarse aggregates on transverse crack performance in jointed concrete pavements, ACI Materials Journal May-June2000), 325-332.

[12] C.Y. Chan, F.K. Fong, Development in recycling of construction and demolition materials, in: (Civil Engineering Department, Hong Kong, 2002).

[13] J. Farran, Contribution of microstructure of minerals and their bonding with Portland cement paste, Rev, Material, Construction, Travel Publics1956), 490-491.

[14] W. Jia, L. Baoyuan, X. Songshan, W. Zhongwei, Improvement of paste-aggregate interface by adding silica fume, in: Proceedings of the 8th International Congress on the Chemistry of Cement (1986) 460-465.

[15] H. Kawano, The state of reuse of demolished concrete in Japan, in: Integrated design and environmental issues in concrete technology: proceedings of the International Workshop 'Rational Design of Concrete Structures under Severe Conditions' (London: E \& FN Spon, Hakodate, Japan, 1995) 243-249. 
[16] W. Keru, Z. Jianhua, The influence of the matrix-aggregate bond on the strength and brittleness of concrete, Bonding in Cementitious Composites, Materials Research Society 1141988), 29-34.

[17] A.K.H. Kwan, Z.M. Wang, H.C. Chan, Mesoscopic study of concrete II: nonlinear finite element analysis, Computers and Structures 70(5), (1999), 545-556.

[18] J.A. Larbi, The cement paste-aggregate interfacial zone in concreteTechnical University of Delft, 1991.

[19] G. Li, H. Xie, G. Xiong, Transition zone studies of new-to-old concrete with different binders, Cement and Concrete Composites 23(4-5), (2001), 381-387.

[20] Y.T. Lo, Microstructure study of the aggregate/cement paste interfacial zone of lightweight concrete, Department of Building and Construction, City University of Hong Kong, 2000.

[21] P.K. Mehta, P.C. Aitcin, Microstructural basis of selection of materials and mix proportions for high strength concrete, High Strength Concrete, Second International Symposium, ACI SP-1211990), 265-279.

[22] K. Mitsui, Z. Li, D.A. Lange, S.P. Shah, Relationship between microstructure and mechanical properties of the paste-aggregate interface, ACI Materials Journal 91(1), (1994), 30-39.

[23] A.R. Mohamed, W. Hansen, Micromechanical modeling of crack-aggregate interaction in concrete materials, Cement and Concrete Composites 21(5-6), (1999), 349-359.

[24] F.T. Olorunsogo, N. Padayachee, Performance of recycled aggregate concrete monitoring by durability indexes, Cement and Concrete Research 32(2), (2002), 179185. 
[25] S. Popovics, Attempts to improve the bond between cement paste and aggregate, Materials and Structures 20(115), (1987), 32-38.

[26] R.S. Ravindrarajah, C.T. Tam, Methods of improving the quality of recycled aggregate concrete, in: Demolition and reuse of concrete and masonry: reuse of demolition waste (London: Chapman and Hall, 1988) 575-584.

[27] K.L. Scrivener, K.M. Nemati, The percolation of pore space in the cement paste/aggregate interfacial zone of concrete, Cement and Concrete Research 26(1), (1996), 35-40.

[28] M.A. Tasdemir, C. Tasdemir, S. Akyuz, A.D. Jefferson, F.D. Lydon, B.I.G. Barr, Evaluation of strains at peak stresses in concrete: a three-phase composite model approach, Cement and Concrete Composites 20(4), (1998), 301-318.

[29] F. Tomosawa, T. Noguchi, New technology for the recycling of concrete - Japanese experience, in: Concrete technology for a sustainable development in the 21st century (London: New York: E \& FN Spon, 2000) 274-287.

[30] Z.M. Wang, A.K.H. Kwan, H.C. Chan, Mesoscopic study of concrete I: generation of random aggregate structure and finite element mesh, Computers and Structures 70(5), (1999), 533-544.

[31] W. Xueqan, L. Dongxu, B. Qinghan, G. Liqun, T. Minshu, Preliminary study of a composite process in concrete manufacture, Cement and Concrete Research 17(5), (1987), 709-714.

[32] R. Zaharieva, F. Buyle-Bodin, F. Skoczylas, E. Wirquin, Assessment of the surface permeation properties of recycled aggregate concrete, Cement and Concrete Composites 25(2), (2003), 223-232.

[33] P.H. Emmons, A.M. Vaysburd, System concept in design and construction of durable concrete repairs, Construction and Building Materials 10(1), (1996), 69-75. 
[34] M. Kikuchi, A. Yasunaga, K. Ehara, The total evaluation of recycled aggregate and recycled concrete, in: Demolition and reuse of concrete and masonry, Proceedings of the third international RILEM symposium (E\&FN Spon, 1994) 367-378.

[35] B.H. Oh, S.W. Cha, B.S. Jang, S.Y. Jang, Development of high-performance concrete having high resistance to chloride penetration, Nuclear Engineering and Design 212(1-3), (2002), 221-231.

[36] K. Sakai, N. Banthia, Integrated design of concrete structures and technology development, in: Concrete Technology for a Sustainable Development in the 21st century (E\&FN Spon, London, 2000) 14-26.

[37] M.A. Sanjuan, R. Munoz-Martialay, Modelling of the concrete air permeability evolution over time, Materials Letters 27(4-5), (1996), 269-272.

[38] M. Zakaria, J.G. Cabrera, Performance and durability of concrete made with demolition waste and artificial fly ash-clay aggregates, Waste Management 16(1-3), (1996), 151-158.

[39] Buildings Department, in: (2005).

[40] Y. Kasai, Recent trends in recycling of concrete waste and use of recycled aggregate concrete in Japan, in: Recycling concrete and other materials for sustainable development (2004) 11-34.

[41] M. Kikuchi, T. Mukai, H. Koizumi, Properties of concrete products containing recycled aggregate, in: Demolition and reuse of concrete and masonry: reuse of demolition waste (London: Chapman and Hall, 1988) 595-604.

[42] Hong Kong Government, Construction standard: testing concrete (Hong Kong Government, 1990). 
[43] F. Benboudjema, F. Meftah, J.M. Torrenti, Interaction between drying shrinkage, creep and cracking phenomena in concrete, Engineering Structure 27(2), (2005), 239250.

[44] Z. Liu, J.J. Beaudoin, The permeability of cement systems to chloride ingress and related test methods, Cement, Concrete and Aggregates 22(1), (2000), 16-23.

[45] I.B. Topcu, S. Sengel, Properties of concretes produced with waste concrete aggregate, Cement and Concrete Research 34(8), (2004), 1307-1312.

[46] P.C. Hewlett, Lea's chemistry of cement and concrete (London: Arnold, 1998).

[47] P.K. Mehta, J.M. Monteiro, Concrete: structure, properties, and materials (1993).

[48] S. Mindess, F. Young, D. Darwin, Concrete (2003).

[49] A.M. Neville, Properties of concrete (1995).

[50] B.I.G. Barr, S.B. Hoseinian, M.A. Beygi, Shrinkage of concrete stored in natural environment, Cement and Concrete Composites 25(1), (2003), 19-29.

[51] E. Holt, Contribution of mixture design to chemical and autogenous shrinkage of concrete at early ages, Cement and Concrete Research 35(3), (2005), 464-472.

[52] E. Holt, M. Leivo, Cracking risks associated with early age shrinkage, Cement and Concrete Composites 26(5), (2004), 521-530.

[53] B. Rongbing, S. Jian, Synthesis and evaluation of shrinkage-reducing admixture for cementitious materials, Cement and Concrete Research 35(3), (2005), 445-448.

[54] A. Ajdukiewicz, A. Kliszuzewicz, Influence of recycled aggregates on mechanical properties of HS/HPC, Cement and Concrete Composites 24(2), (2002), 269-279.

[55] A. Katz, Properties of concrete made with recycled aggregate from partially hydrated old concrete, Cement and Concrete Research 33(5), (2003), 703-711. 
[56] H.A. Mesbah, F. Buyle-Bodin, Efficiency of polypropylene and metallic fibres on control of shrinkage and cracking of recycled aggregate mortars, Construction and Building Materials 13(8), (1999), 439-447.

[57] J. Figg, Early age permeability measurements for prediction of concrete durability, in: Durability of concrete: G.M. Idorn International Symposium (Detroit, Mich.: American Concrete Institute, 1992) 289-303.

[58] M. Ghalibafian, M. Shekarchi, A. Zare, M. Tasdaiion, Chloride penetraton testing of silica fume concretes under Persian gulf conditions, in: Sixth Canmet / ACI International Conference on Durability of Concrete (Farmington Hills, Mich.: ACI International, 2003) 737-753.

[59] BS 1881: Part 5, Determination of changes in length on drying and wetting, British Standard Institution, United Kingdom, 1970.

[60] ASTM C512-02, Standard test method for creep of concrete in compression, American Society for Testing and Materials, United States, 2002.

[61] AASHTO T277 (American Association of State Highway and Transportation Officials), Rapid determination of the chloride permeability of concrete, American Association of State Highway and Transportation Officials, United States of American, 1983. 
Table 1: Reuse of Demolished Concrete [7]

\begin{tabular}{|l|l|}
\hline Demolished Member & Man-made Reef, Paving Stone \\
\hline Broken into 20 to $40 \mathrm{~cm}$ & Protection of Levee \\
\hline Crushed (-50mm) & Sub-base, Backfilling, Foundation Materials \\
\hline Crushed and Worn (-40mm) & $\begin{array}{l}\text { Concrete and Asphalt Concrete Aggregate Sub- } \\
\text { Base Material, Backfilling Material }\end{array}$ \\
\hline Powder (by-product through crushing) & $\begin{array}{l}\text { Filler for Asphalt Concrete, Soil Stabilization } \\
\text { Materials }\end{array}$ \\
\hline
\end{tabular}


Table 2: Mix Proportions [39]

\begin{tabular}{|c|c|}
\hline Ingredients of concrete & Mass (in kg) \\
\hline Ordinary Portland cement & 100 \\
\hline Fine aggregate & 180 \\
\hline 20mm coarse aggregate & 180 \\
\hline 10mm coarse aggregate & 90 \\
\hline Water & 45 \\
\hline
\end{tabular}


Table 3: Standards Controlling the Properties of Concrete

\begin{tabular}{|l|l|}
\hline Properties of Concrete & Standard \\
\hline Deformation & BS 1881: Part 5 [59] \\
\hline Shrinkage & ASTM C512-02 [60] \\
\hline Creep & Manual of GWT-4170 kit \\
\hline Permeability & Manual of P-6000 Poroscope \\
\hline Water permeability & $\begin{array}{l}\text { American Association of } \\
\text { State Highway and } \\
\text { Air permeability } \\
\text { Chloride permeability } \\
\end{array}$ \\
\hline 61$]$
\end{tabular}


Table 4: Parameters Affecting Deformation of Concrete [48]

\begin{tabular}{|l|l|}
\hline Paste parameters & $\begin{array}{l}\text { Porosity } \\
\text { Age of paste } \\
\text { Curing temperature } \\
\text { Cement composition } \\
\text { Moisture content } \\
\text { Admixtures }\end{array}$ \\
\hline Concrete parameters & $\begin{array}{l}\text { Aggregate stiffness } \\
\text { Aggregate content } \\
\text { Volume-surface ratio } \\
\text { Thickness }\end{array}$ \\
\hline Environmental & Applied stress \\
parameters & Duration offload \\
& Relative humidity \\
& Rate of drying \\
& Time of drying \\
\hline
\end{tabular}


Table 5: Shrinkage Results for RAC

\begin{tabular}{|c|c|c|c|c|c|c|}
\hline \multirow{3}{*}{ Days } & \multicolumn{6}{|c|}{ Shrinkage (in \%) } \\
\hline & \multicolumn{3}{|c|}{ NMA } & \multicolumn{3}{|c|}{ TSMA } \\
\hline & $0 \%$ & $20 \%$ & $100 \%$ & $0 \%$ & $20 \%$ & $100 \%$ \\
\hline 14 & $0.005 \%$ & $0.007 \%$ & $0.011 \%$ & $0.011 \%$ & $0.006 \%$ & $0.003 \%$ \\
\hline 28 & $0.019 \%$ & $0.015 \%$ & $0.022 \%$ & $0.021 \%$ & $0.014 \%$ & $0.014 \%$ \\
\hline 42 & $0.049 \%$ & $0.044 \%$ & $0.051 \%$ & $0.046 \%$ & $0.047 \%$ & $0.035 \%$ \\
\hline 56 & $0.062 \%$ & $0.075 \%$ & $0.070 \%$ & $0.064 \%$ & $0.062 \%$ & $0.062 \%$ \\
\hline 70 & $0.072 \%$ & $0.074 \%$ & $0.080 \%$ & $0.070 \%$ & $0.078 \%$ & $0.074 \%$ \\
\hline 84 & $0.078 \%$ & $0.080 \%$ & $0.091 \%$ & $0.083 \%$ & $0.083 \%$ & $0.089 \%$ \\
\hline 98 & $0.083 \%$ & $0.088 \%$ & $0.096 \%$ & $0.086 \%$ & $0.089 \%$ & $0.092 \%$ \\
\hline 112 & $0.095 \%$ & $0.095 \%$ & $0.103 \%$ & $0.095 \%$ & $0.095 \%$ & $0.100 \%$ \\
\hline 126 & $0.099 \%$ & $0.102 \%$ & $0.110 \%$ & $0.101 \%$ & $0.102 \%$ & $0.108 \%$ \\
\hline 140 & $0.108 \%$ & $0.109 \%$ & $0.118 \%$ & $0.112 \%$ & $0.110 \%$ & $0.116 \%$ \\
\hline 154 & $0.114 \%$ & $0.115 \%$ & $0.125 \%$ & $0.117 \%$ & $0.115 \%$ & $0.120 \%$ \\
\hline 168 & $0.120 \%$ & $0.118 \%$ & $0.128 \%$ & $0.121 \%$ & $0.118 \%$ & $0.126 \%$ \\
\hline 182 & $0.121 \%$ & $0.123 \%$ & $0.131 \%$ & $0.124 \%$ & $0.122 \%$ & $0.129 \%$ \\
\hline \multicolumn{7}{|c|}{ Rewetting } \\
\hline 189 & $0.098 \%$ & $0.095 \%$ & $0.106 \%$ & $0.100 \%$ & $0.093 \%$ & $0.099 \%$ \\
\hline 196 & $0.089 \%$ & $0.088 \%$ & $0.101 \%$ & $0.091 \%$ & $0.088 \%$ & $0.095 \%$ \\
\hline 203 & $0.088 \%$ & $0.087 \%$ & $0.100 \%$ & $0.088 \%$ & $0.086 \%$ & $0.093 \%$ \\
\hline 210 & $0.088 \%$ & $0.086 \%$ & $0.099 \%$ & $0.087 \%$ & $0.085 \%$ & $0.092 \%$ \\
\hline
\end{tabular}


Table 6: Creep Strain and Creep Coefficient for RAC

\begin{tabular}{|c|c|c|c|c|c|c|c|c|c|c|c|c|}
\hline \multirow{3}{*}{$\mathrm{t}$} & \multicolumn{6}{|c|}{$\mathrm{CS}_{\mathrm{t}}^{\wedge} *$} & \multicolumn{6}{|c|}{$\mathrm{CC}_{\mathrm{t}}^{\wedge} *$} \\
\hline & \multicolumn{3}{|c|}{ NMA } & \multicolumn{3}{|c|}{ TSMA } & \multicolumn{3}{|c|}{ NMA } & \multicolumn{3}{|c|}{ TSMA } \\
\hline & $0 \%$ & $20 \%$ & $100 \%$ & $0 \%$ & $20 \%$ & $100 \%$ & $0 \%$ & $20 \%$ & $100 \%$ & $0 \%$ & $20 \%$ & $100 \%$ \\
\hline 14 & 0.000146 & 0.000215 & 0.000461 & 0.000133 & 0.000134 & 0.000247 & 1.46 & 2.15 & 4.61 & 1.33 & 1.34 & 2.47 \\
\hline 28 & 0.000219 & 0.000320 & 0.000669 & 0.000216 & 0.000238 & 0.000493 & 2.19 & 3.20 & 6.69 & 2.16 & 2.38 & 4.93 \\
\hline 42 & 0.000291 & 0.000398 & 0.000799 & 0.000280 & 0.000301 & 0.000630 & 2.91 & 3.98 & 7.99 & 2.80 & 3.01 & 6.30 \\
\hline 56 & 0.000326 & 0.000459 & 0.000930 & 0.000323 & 0.000361 & 0.000741 & 3.26 & 4.59 & 9.30 & 3.23 & 3.61 & 7.41 \\
\hline 70 & 0.000371 & 0.000517 & 0.001040 & 0.000373 & 0.000396 & 0.000822 & 3.71 & 5.17 & 10.40 & 3.73 & 3.96 & 8.22 \\
\hline 84 & 0.000390 & 0.000557 & 0.001117 & 0.000404 & 0.000457 & 0.000902 & 3.90 & 5.57 & 11.17 & 4.04 & 4.57 & 9.02 \\
\hline 98 & 0.000443 & 0.000597 & 0.001196 & 0.000430 & 0.000488 & 0.000952 & 4.43 & 5.97 & 11.96 & 4.30 & 4.88 & 9.52 \\
\hline 112 & 0.000473 & 0.000636 & 0.001267 & 0.000445 & 0.000528 & 0.001003 & 4.73 & 6.36 & 12.67 & 4.45 & 5.28 & 10.03 \\
\hline 126 & 0.000501 & 0.000667 & 0.001335 & 0.000482 & 0.000559 & 0.001058 & 5.01 & 6.67 & 13.35 & 4.82 & 5.59 & 10.58 \\
\hline 140 & 0.000510 & 0.000691 & 0.001376 & 0.000485 & 0.000569 & 0.001102 & 5.10 & 6.91 & 13.76 & 4.85 & 5.69 & 11.02 \\
\hline 154 & 0.000533 & 0.000725 & 0.001441 & 0.000502 & 0.000593 & 0.001132 & 5.33 & 7.25 & 14.41 & 5.02 & 5.93 & 11.32 \\
\hline 168 & 0.000549 & 0.000753 & 0.001486 & 0.000517 & 0.000618 & 0.001176 & 5.50 & 7.53 & 14.86 & 5.17 & 6.18 & 11.76 \\
\hline 182 & 0.000563 & 0.000754 & 0.001517 & 0.000530 & 0.000633 & 0.001176 & 5.63 & 7.54 & 15.17 & 5.230 & 6.33 & 11.76 \\
\hline \multicolumn{13}{|c|}{ Unloading } \\
\hline 7 days & 0.000038 & 0.000189 & 0.000806 & 0.000012 & 0.000079 & 0.000722 & 0.38 & 1.89 & 8.06 & 0.12 & 0.79 & 7.22 \\
\hline 14 days & 0.000019 & 0.000161 & 0.000782 & 0.000012 & 0.000054 & 0.000667 & 0.19 & 1.61 & 7.82 & 0.12 & 0.54 & 6.67 \\
\hline 21 days & 0.000017 & 0.000140 & 0.000761 & 0.000012 & 0.000041 & 0.000610 & 0.17 & 1.40 & 7.61 & 0.12 & 0.41 & 6.10 \\
\hline 28 days & 0.000015 & 0.000129 & 0.000743 & 0.000012 & 0.000024 & 0.000575 & 0.15 & 1.29 & 7.43 & 0.12 & 0.24 & 5.75 \\
\hline \multicolumn{13}{|c|}{$\begin{array}{l}\text { Note: } \\
\wedge \text { The specimens are loaded for the first } 182 \text { days; and then unloaded for another } 28 \text { days (until day 210). } \\
* \text { The creep strain and creep coefficient are measured by Equations (1) and (2) respectively. }\end{array}$} \\
\hline \multicolumn{7}{|c|}{$C C_{t}=\frac{C S_{t}}{\frac{1}{E}}$} & & & & & & \\
\hline \multicolumn{13}{|c|}{$\frac{1}{E}$ is the initial elastic strain; $S_{t}$ is the } \\
\hline
\end{tabular}


Table 7: Creep Constant for RAC

\begin{tabular}{|c|c|c|c|c|c|c|}
\hline \multirow{2}{*}{ Creep Constant* } & \multicolumn{3}{|c|}{ NMA } & \multicolumn{3}{|c|}{ TSMA } \\
\hline & $0 \%$ & $20 \%$ & $100 \%$ & $0 \%$ & $20 \%$ & $100 \%$ \\
\hline$\frac{1}{E}$ & 0.0001 & 0.0001 & 0.0001 & 0.0001 & 0.0001 & 0.0001 \\
\hline $\mathrm{F}(\mathrm{K})$ & 0.00002 & 0.00003 & 0.00005 & 0.00002 & 0.00002 & 0.00005 \\
\hline \multicolumn{7}{|c|}{$\begin{array}{l}\text { Note: } \\
\text { * The creep constant of initial elastic strain }\left(\frac{1}{E}\right) \text { and creep rate }[\mathrm{F}(\mathrm{K})] \text {, can be estimated } \\
\text { by fitting a curve in Equation (3). }\end{array}$} \\
\hline & $\varepsilon_{t}=\left(\frac{1}{E}\right.$ & $+F(K) I$ & $+1)$ & Equation & & \\
\hline \multicolumn{7}{|c|}{$\begin{array}{l}\text { Where } \varepsilon_{t} \text { is the measured strain at time } t ; \frac{1}{E} \text { is the initial elastic strain; } F(K) \text { is the creep } \\
\text { rate (in strain/day); and } t \text { is the time after loading (in days). }\end{array}$} \\
\hline
\end{tabular}


Table 8: Reversible and Irreversible Parts on Shrinkage and Creep

\begin{tabular}{|c|c|c|c|c|c|c|c|}
\hline \multirow{2}{*}{ Mixing Method } & \multicolumn{6}{|c|}{ Percentage (\%) } \\
\cline { 3 - 8 } \multicolumn{2}{|c|}{} & \multicolumn{3}{|c|}{ NMA } & \multicolumn{3}{c|}{ TSMA } \\
\cline { 3 - 8 } & $0 \%$ & $20 \%$ & $100 \%$ & $0 \%$ & $20 \%$ & $100 \%$ \\
\hline \multirow{2}{*}{ Shrinkage } & Reversible & $27.73 \%$ & $29.98 \%$ & $24.56 \%$ & $27.88 \%$ & $30.00 \%$ & $28.70 \%$ \\
\cline { 2 - 8 } & Irreversible & $72.27 \%$ & $70.02 \%$ & $75.44 \%$ & $72.12 \%$ & $70.00 \%$ & $71.30 \%$ \\
\hline \multirow{2}{*}{ Creep } & Reversible & $97.34 \%$ & $82.89 \%$ & $51.02 \%$ & $97.74 \%$ & $96.21 \%$ & $51.11 \%$ \\
\cline { 2 - 8 } & Irreversible & $2.66 \%$ & $17.11 \%$ & $48.98 \%$ & $2.26 \%$ & $3.79 \%$ & $48.89 \%$ \\
\hline
\end{tabular}


Table 9: Water Permeability for RAC

\begin{tabular}{|c|c|c|c|c|c|c|}
\hline \multirow{3}{*}{ Curing days } & \multicolumn{6}{|c|}{ Water permeability (in $\mathrm{mm}^{2} / \mathrm{s} . \mathrm{BAR}$ ) } \\
\hline & \multicolumn{3}{|c|}{ NMA } & \multicolumn{3}{|c|}{ TSMA } \\
\hline & $0 \%$ & $20 \%$ & $100 \%$ & $0 \%$ & $20 \%$ & $100 \%$ \\
\hline 14 & 0.00786 & 0.00723 & 0.00887 & 0.00716 & 0.00737 & 0.00722 \\
\hline 28 & 0.00734 & 0.00832 & 0.00719 & 0.00697 & 0.00813 & 0.00678 \\
\hline 42 & 0.00733 & 0.00737 & 0.00723 & 0.00673 & 0.00770 & 0.00744 \\
\hline 56 & 0.00747 & 0.00855 & 0.00786 & 0.00728 & 0.00793 & 0.00866 \\
\hline 70 & 0.00829 & 0.00114 & 0.00150 & 0.00131 & 0.00121 & 0.00146 \\
\hline 84 & 0.00120 & 0.00121 & 0.00140 & 0.00109 & 0.00122 & 0.00113 \\
\hline 98 & 0.00152 & 0.00117 & 0.00137 & 0.00111 & 0.00121 & 0.00120 \\
\hline 112 & 0.00132 & 0.00163 & 0.00144 & 0.00101 & 0.00117 & 0.00122 \\
\hline 126 & 0.00134 & 0.00128 & 0.00172 & 0.00132 & 0.00113 & 0.00111 \\
\hline 140 & 0.00173 & 0.00152 & 0.00142 & 0.00124 & 0.00144 & 0.00162 \\
\hline 154 & 0.00139 & 0.00144 & 0.00140 & 0.00129 & 0.00152 & 0.00140 \\
\hline 168 & 0.00138 & 0.00162 & 0.00140 & 0.00147 & 0.00147 & 0.00164 \\
\hline 182 & 0.00128 & 0.00154 & 0.00164 & 0.00139 & 0.00150 & 0.00147 \\
\hline \multicolumn{7}{|c|}{$\begin{array}{l}\text { Note: } \\
\text { The measurement of water permeability changed during the test period; a double-line in separated the } \\
\text { results. }\end{array}$} \\
\hline
\end{tabular}


Table 10: Air Permeability for RAC

\begin{tabular}{|c|c|c|c|c|c|c|}
\hline \multirow{3}{*}{ Curing days } & \multicolumn{6}{|c|}{ Air permeability (in s/ml) } \\
\hline & \multicolumn{3}{|c|}{ NMA } & \multicolumn{3}{|c|}{ TSMA } \\
\hline & $0 \%$ & $20 \%$ & $100 \%$ & $0 \%$ & $20 \%$ & $100 \%$ \\
\hline 14 & 9.64 & 10.81 & 6.73 & 12.54 & 12.72 & 7.91 \\
\hline 28 & 13.90 & 11.12 & 7.10 & 14.15 & 14.70 & 8.77 \\
\hline 42 & 13.65 & 10.04 & 7.60 & 12.18 & 12.61 & 10.94 \\
\hline 56 & 10.603 & 8.28 & 4.72 & 12.01 & 12.57 & 6.99 \\
\hline 70 & 10.55 & 9.74 & 5.75 & 11.67 & 10.34 & 6.26 \\
\hline 84 & 8.84 & 10.77 & 6.35 & 11.67 & 11.97 & 5.40 \\
\hline 98 & 9.65 & 11.45 & 7.08 & 11.28 & 10.55 & 6.61 \\
\hline 112 & 11.28 & 9.27 & 4.80 & 12.18 & 11.28 & 6.31 \\
\hline 126 & 11.50 & 9.10 & 6.35 & 12.05 & 11.32 & 5.83 \\
\hline 182 & 9.01 & 9.74 & 4.55 & 11.24 & 11.28 & 6.56 \\
\hline
\end{tabular}


Table 11: Chloride Permeability for RAC

\begin{tabular}{|c|c|c|c|c|c|c|}
\hline \multirow{2}{*}{ Curing days } & \multicolumn{6}{|c|}{ Chloride permeability (in amperes.s) } \\
\cline { 2 - 6 } & \multicolumn{5}{|c|}{ NMA } & \multicolumn{3}{c|}{ TSMA } & \multicolumn{2}{c|}{$100 \%$} \\
\cline { 2 - 6 } & $0 \%$ & $20 \%$ & $100 \%$ & $0 \%$ & $20 \%$ & 3617.31 \\
\hline 14 & 3753.29 & 3153.53 & 3800.54 & 3248.91 & 3827.90 & 361.85 \\
\hline 28 & 2468.93 & 3054.11 & 2931.48 & 2436.47 & 2487.39 & 3394.85 \\
\hline 42 & 2475.68 & 3025.79 & 3199.16 & 2409.26 & 2301.60 & 2697.59 \\
\hline 56 & 2636.46 & 2269.97 & 2629.22 & 2100.35 & 2911.52 & 2778.94 \\
\hline 70 & 2405.66 & 2606.84 & 2243.48 & 2137.37 & 2414.94 & 2455.22 \\
\hline 84 & 2337.51 & 2410.25 & 2947.68 & 2097.71 & 2728.77 & 2481.16 \\
\hline 98 & 2427.69 & 2615.16 & 2257.86 & 1927.43 & 2596.97 & 2313.65 \\
\hline 112 & 2627.20 & 2766.39 & 3155.49 & 2031.45 & 2739.06 & 2683.31 \\
\hline 126 & 2741.46 & 2211.87 & 3330.50 & 2021.21 & 2811.89 & 2331.85 \\
\hline 182 & 2231.56 & 2703.69 & 2906.60 & 1869.96 & 2121.95 & 2578.04 \\
\hline
\end{tabular}




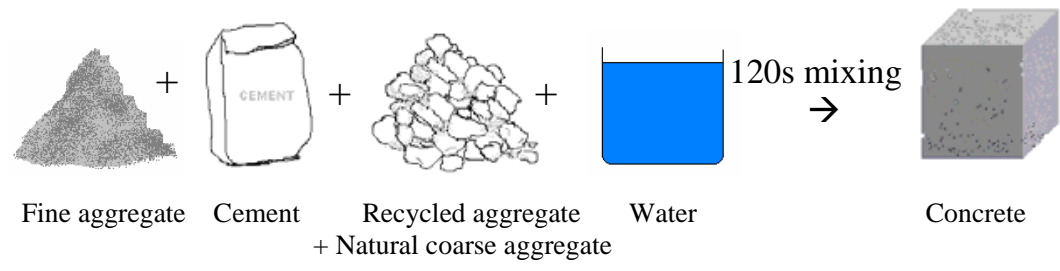

\section{(i) NMA}

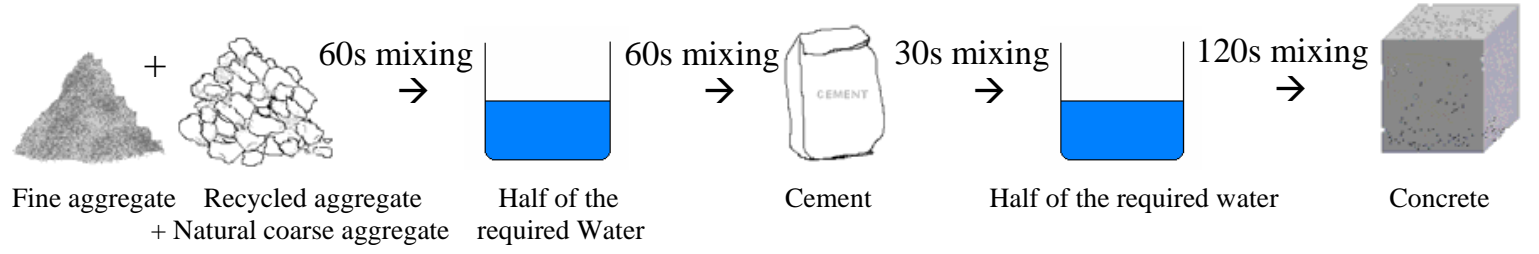

(ii) TSMA

Figure 1: Mixing Procedures of the (i) Normal Mixing Approach and

(ii) Two-Stage Mixing Approach 


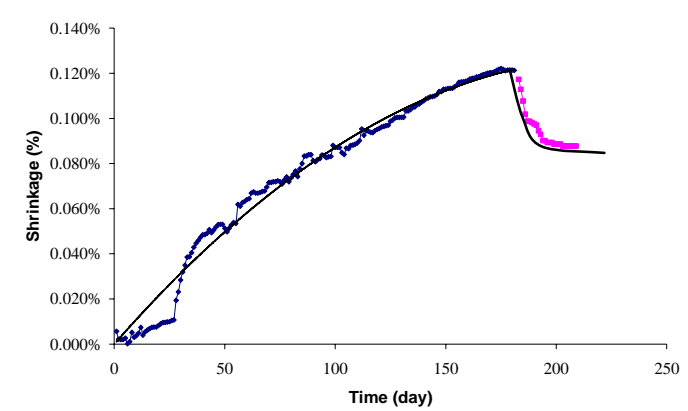

(i)

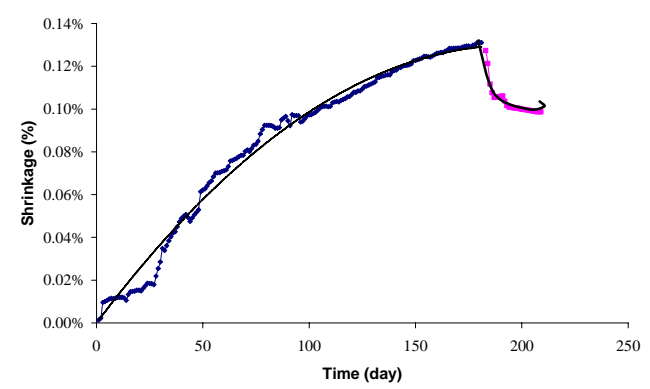

(iii)

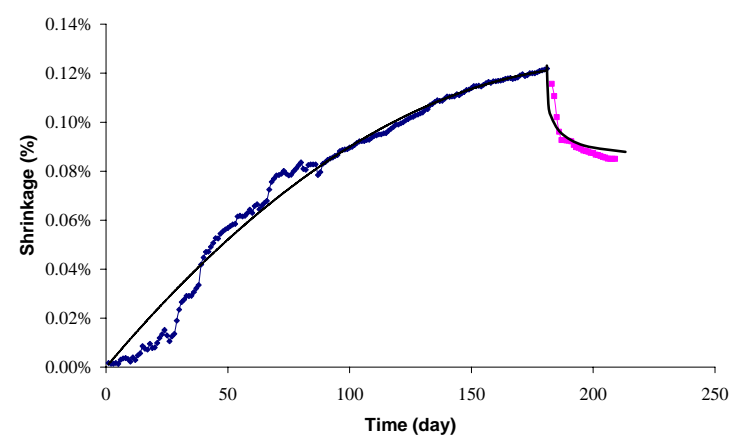

(v)

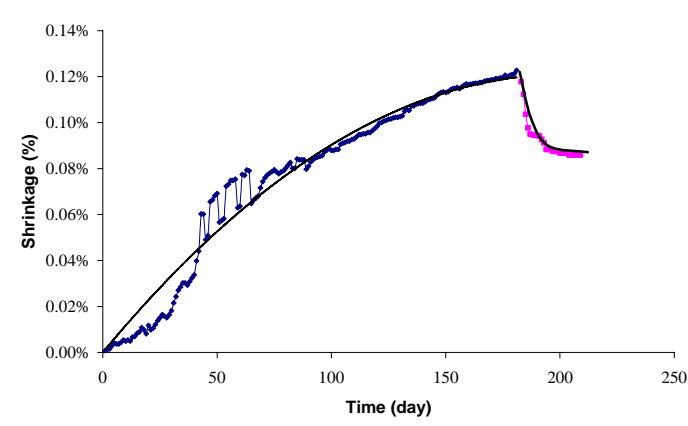

(ii)

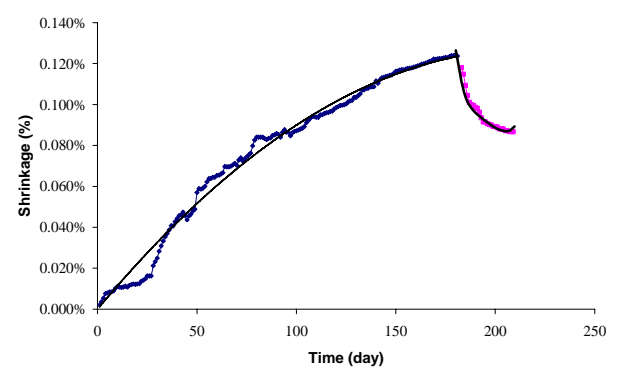

(iv)

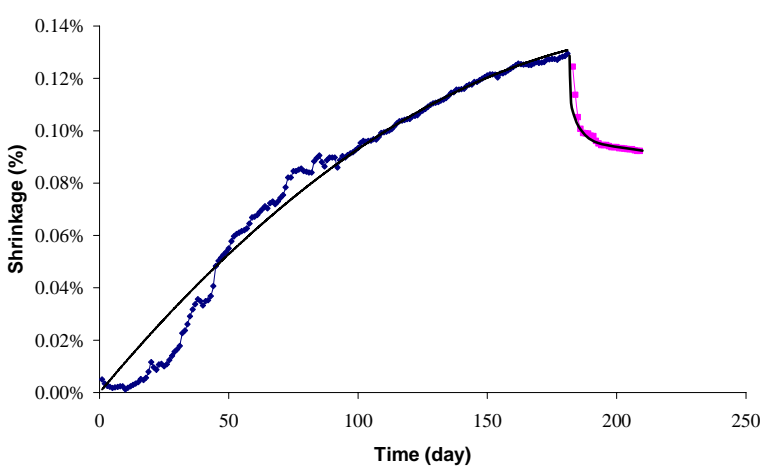

(vi)

Figure 2: Shrinkage deformation behaviour on i) 0\% RA replacement for NMA; ii) 20\% RA replacement for NMA; iii) 100\% RA replacement for NMA; iv) 0\% RA replacement for TSMA; v) 20\% RA replacement for TSMA; and vi) 100\% RA replacement for 


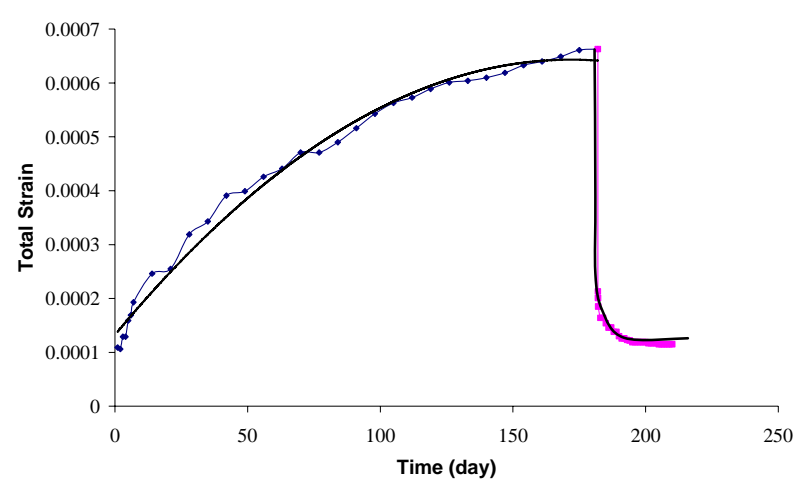

(i)

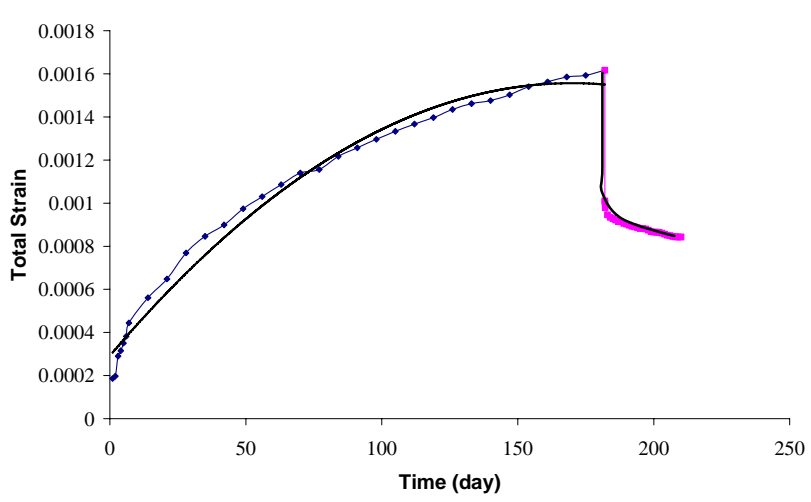

(iii)

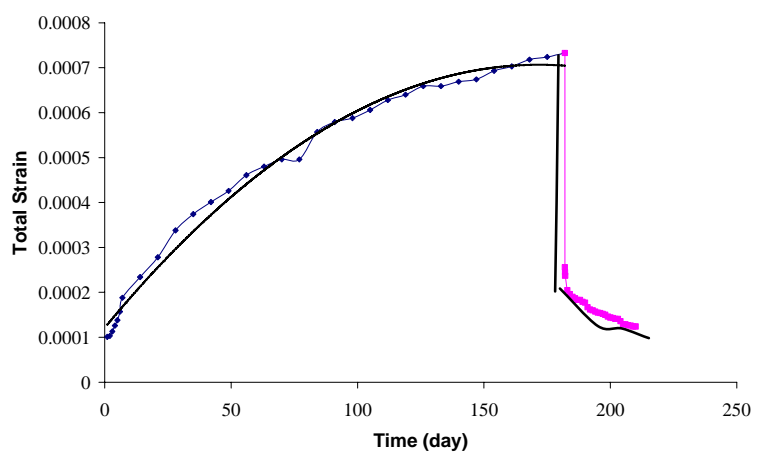

(v)

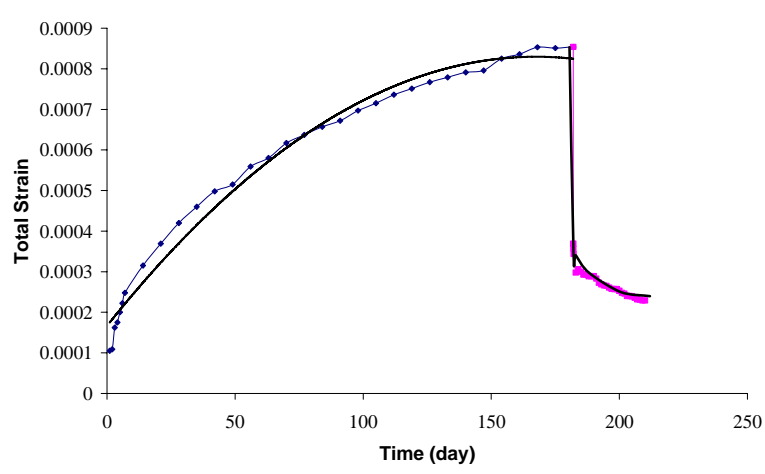

(ii)

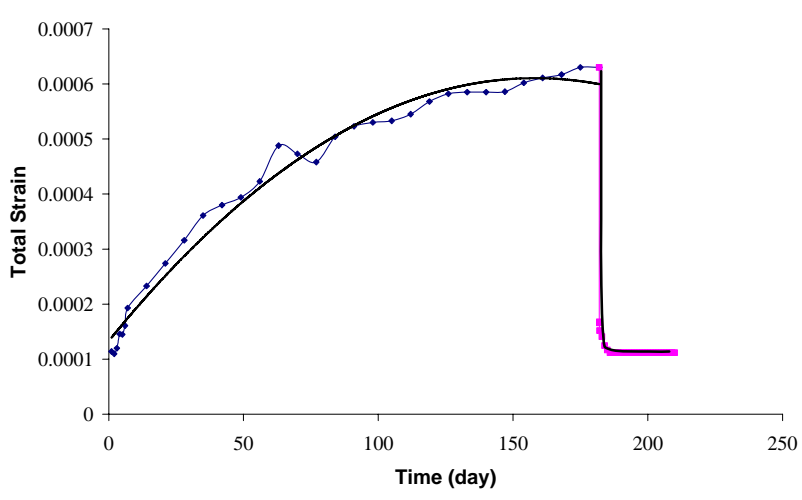

(iv)

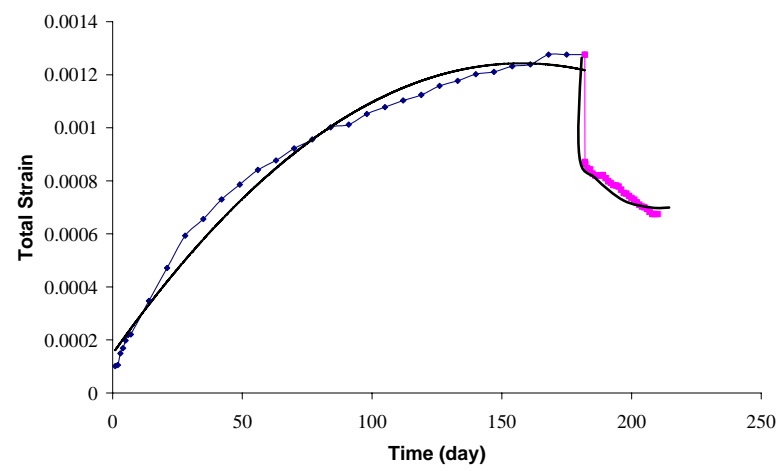

(vi)

Figure 3: Creep deformation behaviour on i) 0\% RA replacement for NMA; ii) 20\% RA replacement for NMA; iii) 100\% RA replacement for NMA; iv) 0\% RA replacement for TSMA; v) 20\% RA replacement for TSMA; and vi) 100\% RA replacement for 


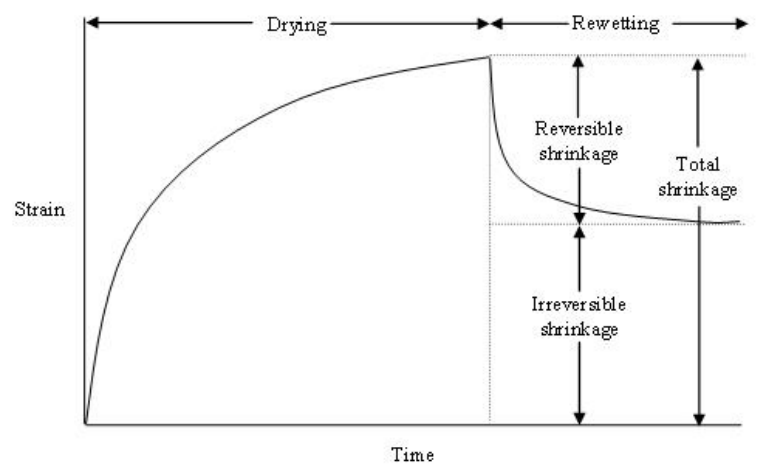

(i)

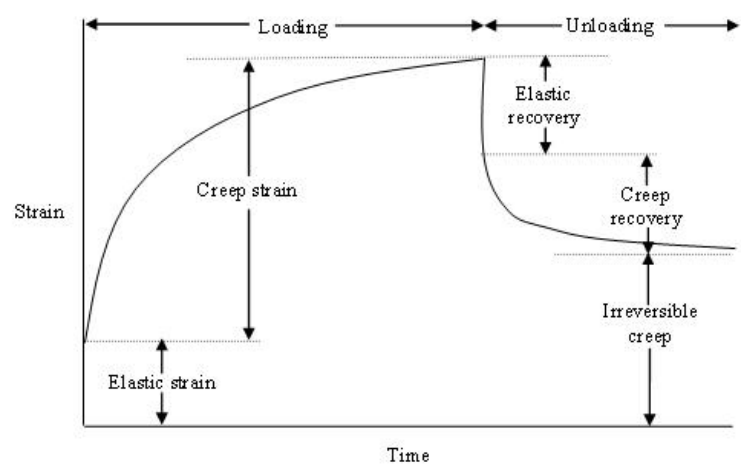

(ii)

Figure 4: Development of (i) Shrinkage; and (ii) Strain, in Concrete [47] 


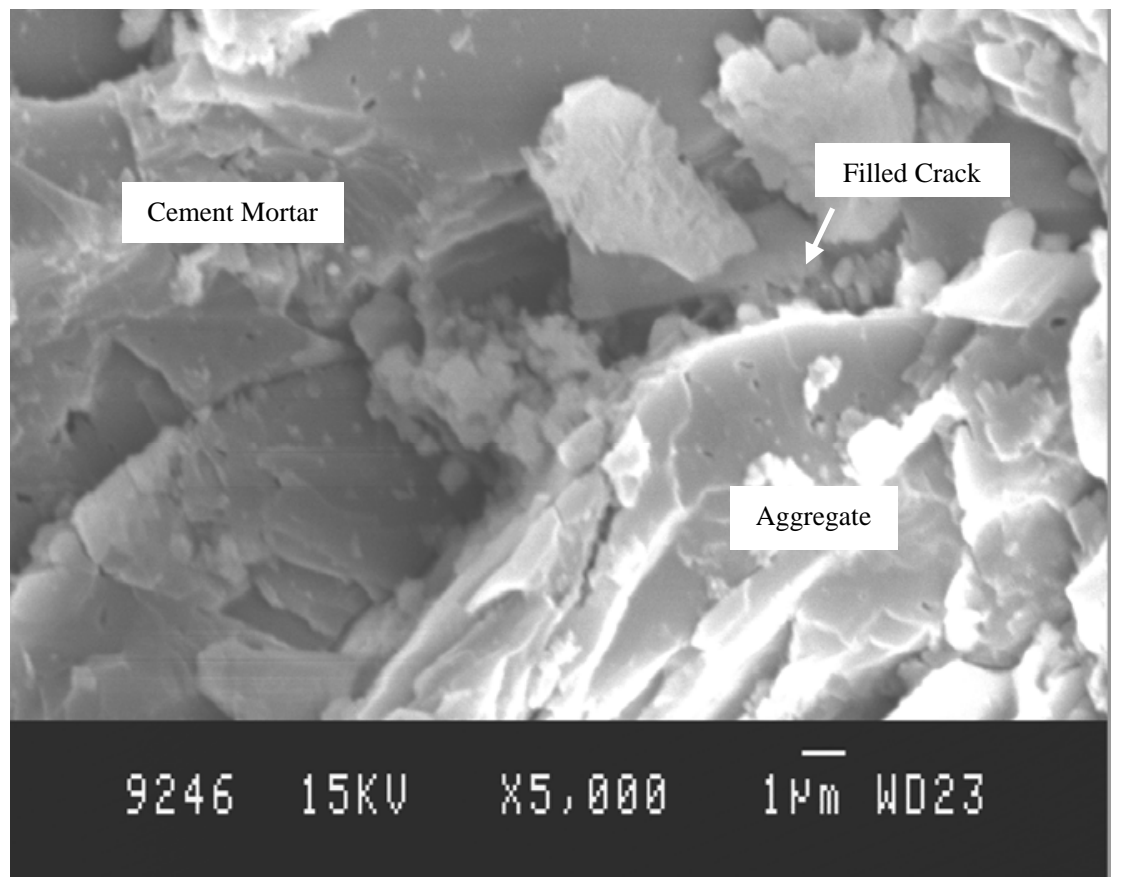

Figure 5: Filled Crack in RA using TSMA 


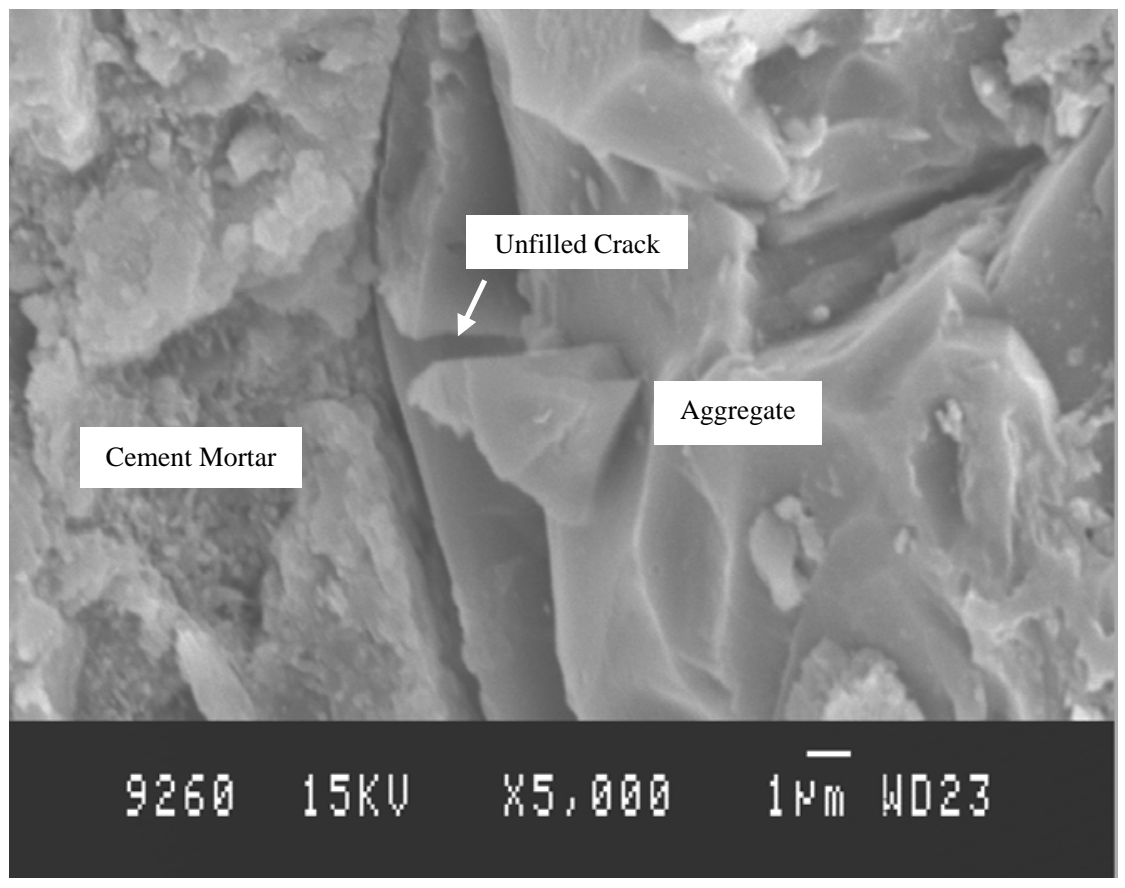

Figure 6: Unfilled Crack in RA using NMA 


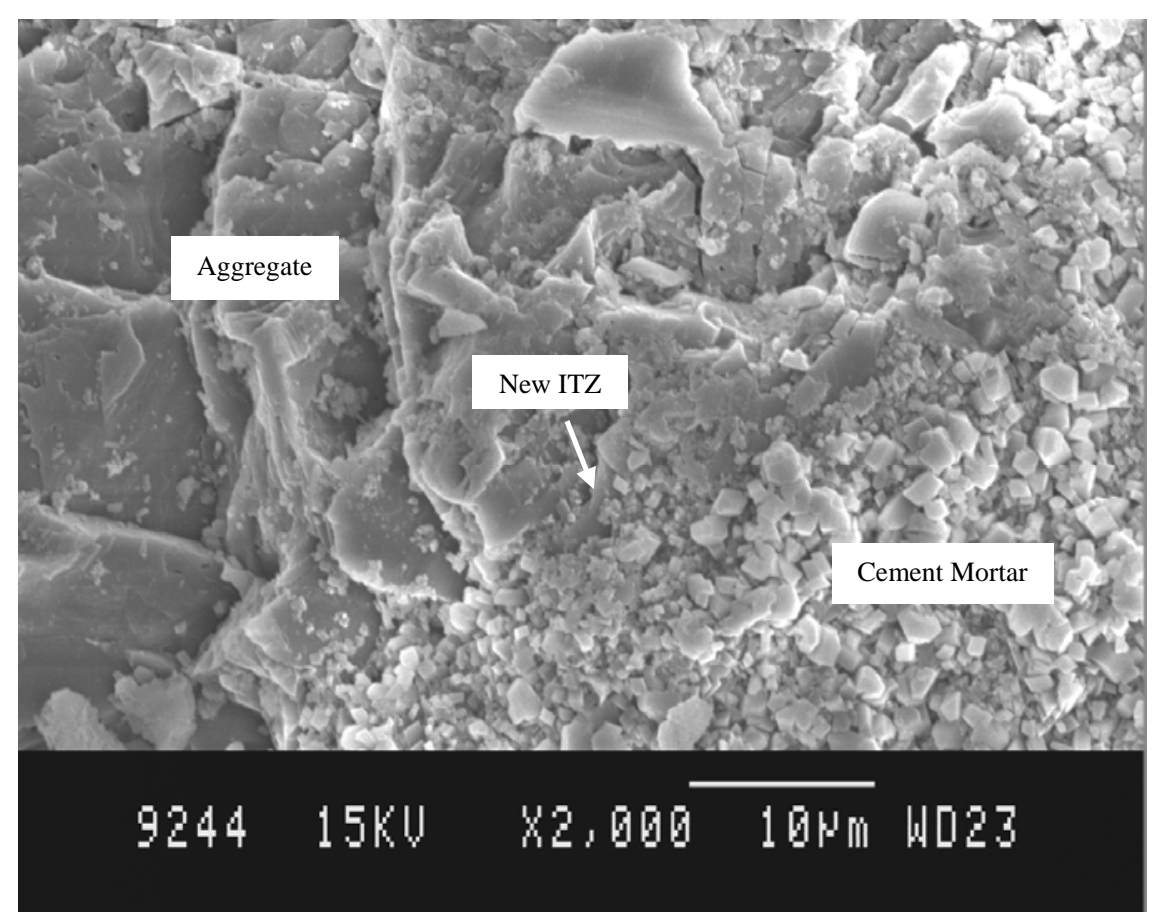

Figure 7: New Interfacial Zone for TSMA 


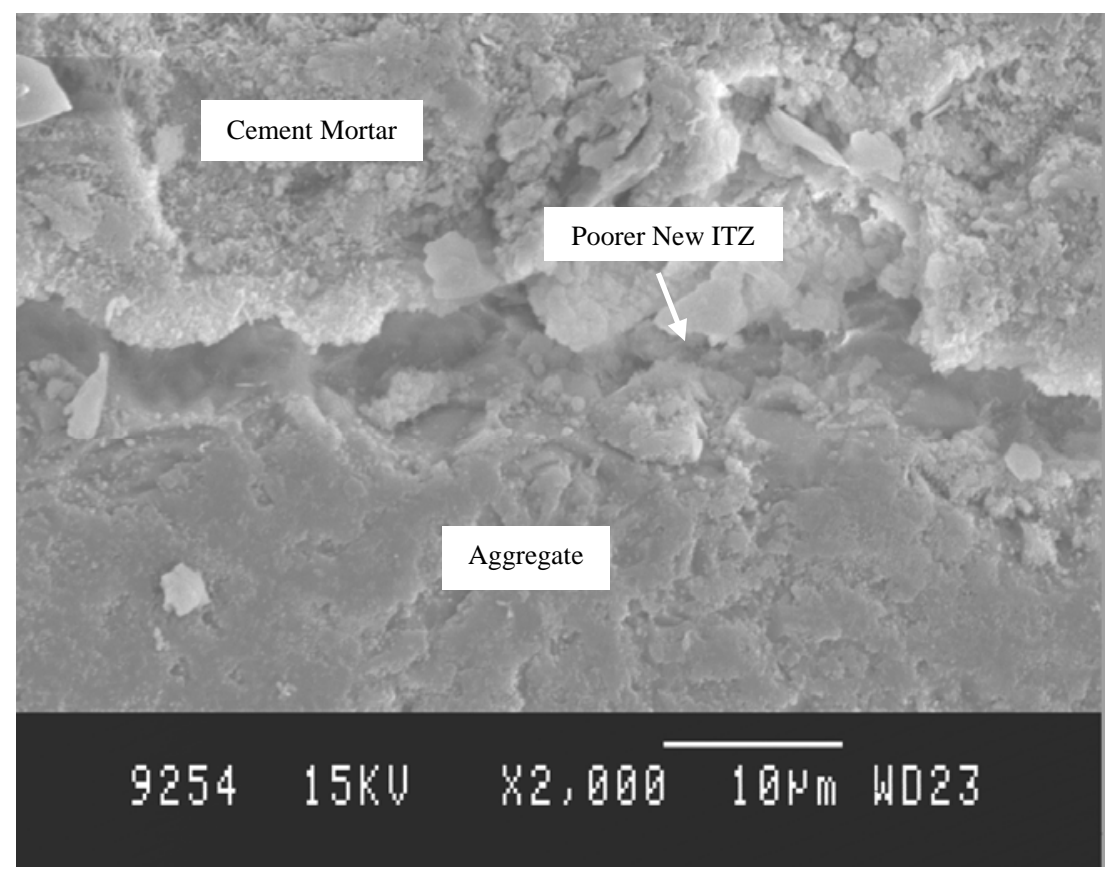

Figure 8: Poorer New Interfacial Zone for NMA 


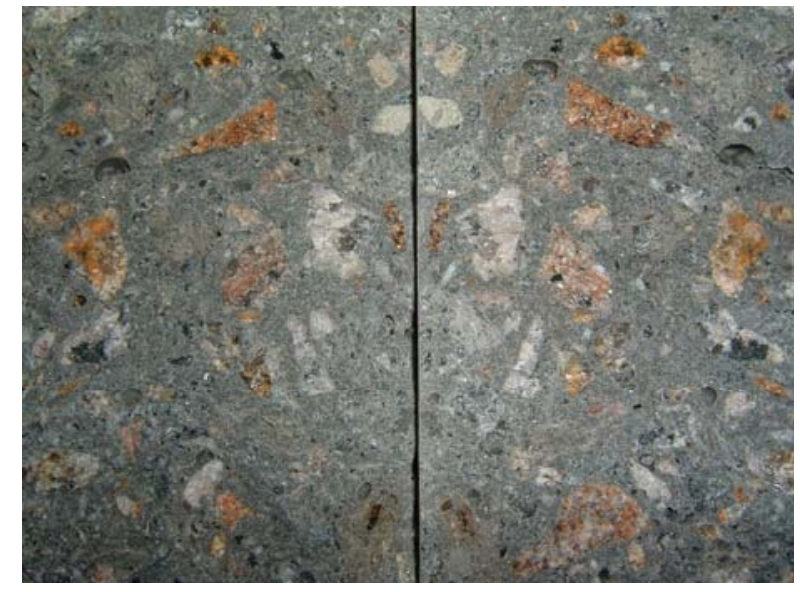

(i)

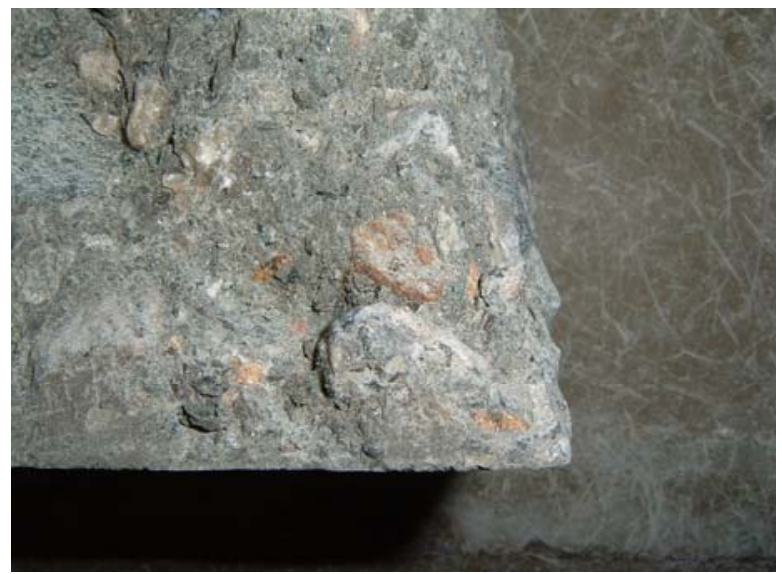

(ii)

Figure 9: Fracture Mode on (i) TSMA; and (ii) NMA 


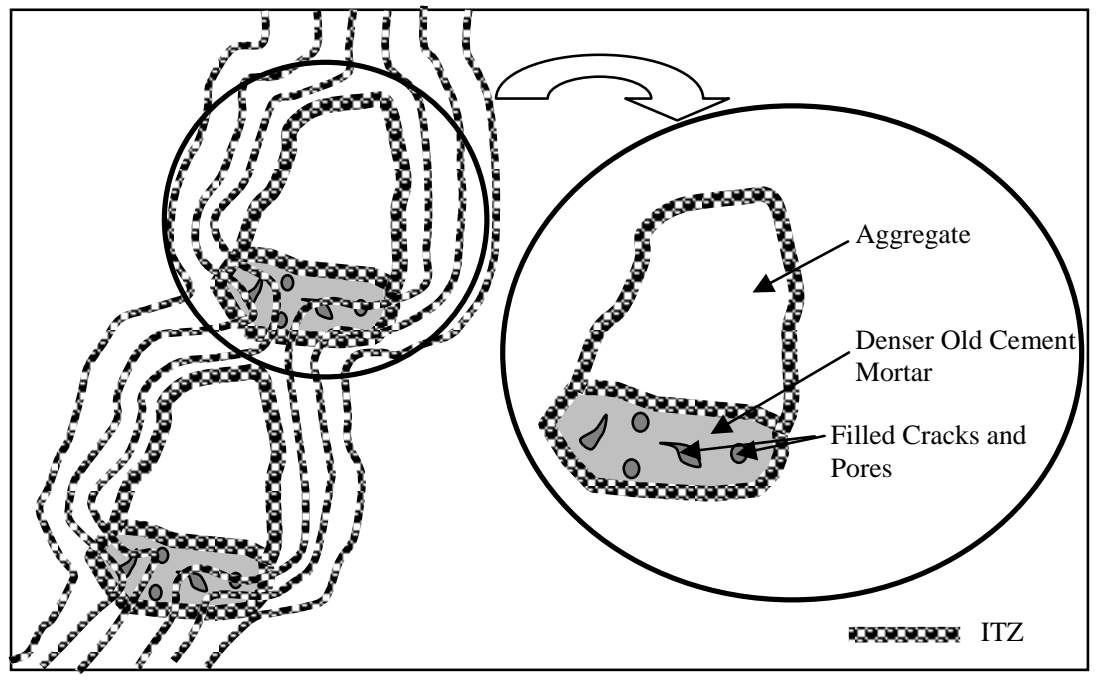

Figure 10: RA Structure after Adopting TSMA 